\title{
In Memoriam: Paolo Bianco
}

\author{
Ivan Martin $^{1} \cdot$ Matteo Centola $^{2} \cdot$ Elia Piccinini $^{3}$
}

Published online: 20 January 2016

(C) Springer International Publishing AG 2016

The community of scientists, politicians, and regulators around the field of stem cell biology has been shocked by the sudden death of Paolo Bianco and by the loss of a passionate, rigorous, deeply honest, inspiring man. We would like to remember Paolo with the eyes of students, as we were when we met him for the first time. The features of his personality that impressed us from the beginning, which we could only confirm in the subsequent years, were his profound knowledge, vigorous critical attitude, and genuine interest to engage in scientific discussions, embedding his strong opinions within a respectful dialogue.

Paolo was more than a scientist; he was a philosopher in its etymological sense of "lover of wisdom." Behind his drive for discovery was a search for the truth, which he pursued by integrating unstructured creativity with logical reasoning. In his quest for knowledge, he was opposed to any possible compromise to moral integrity, which he taught to generations of scientists not only with fine words but also with a model of personal conduct. Paolo was active at all levels, including public debates and policy making, to battle ideological positions and commercial interests that were not based on solid experimental data and the principles of good scientific practice.

The soul of Paolo, beyond any religious belief, continues to live in those students or professionals, who have been inspired by his curiosity, dedication, insightful thinking, and behavior. With his life, he demonstrated aversion to science as a source of power or as a way to merely receive recognition and visibility; to us, he leaves the challenge to carry on these ethical principles as well as his timeless passion for science.

Ivan Martin

ivan.martin@usb.ch

Matteo Centola

matteo.centola@novartis.com

Elia Piccinini

elia.piccinini@utoronto.ca

1 Department of Biomedicine, University Hospital Basel, University of Basel, Basel, Switzerland

2 Musculoskeletal Disease Department, Novartis Pharma AG, Basel, Switzerland

3 The Donnelly Centre for Cellular and Biomolecular Research, University of Toronto, Toronto, ON, Canada 